\title{
Genetic markers for Clostridium difficile lineages linked to hypervirulence
}

\begin{abstract}
Correspondence
Jeroen Corver

j.corver@lumc.nl
\end{abstract}

Received 14 June 2011

Revised 19 August 2011

Accepted 22 August 2011

\author{
Cornelis W. Knetsch, ${ }^{1}$ Marjolein P. M. Hensgens, ${ }^{1}$ Céline Harmanus, ${ }^{1}$ \\ Madelon W. van der Bijl, ${ }^{2}$ Paul H. M. Savelkoul, ${ }^{2}$ Ed J. Kuijper, ${ }^{1}$ \\ Jeroen Corver ${ }^{1}$ and Hans C. van Leeuwen ${ }^{1}$ \\ ${ }^{1}$ Department of Medical Microbiology, Center of Infectious Diseases, Leiden University Medical \\ Center, Leiden, The Netherlands \\ ${ }^{2}$ Department of Medical Microbiology and Infection Control, VU University Medical Center, \\ Amsterdam, The Netherlands
}

Rapid identification of hypervirulent Clostridium difficile strains is essential for preventing their spread. Recent completion of several full-length $C$. difficile genomes provided an excellent opportunity to identify potentially unique genes that characterize hypervirulent strains. Based on sequence comparisons between $C$. difficile strains we describe two gene insertions into the genome of hypervirulent PCR ribotypes 078 and 027. Analysis of these regions, of 1.7 and $4.2 \mathrm{~kb}$, respectively, revealed that they contain several interesting ORFs. The 078 region is inserted intergenically and introduces an enzyme that is involved in the biosynthesis of several antibiotics. The 027 insert disrupts the thymidylate synthetase (thy $X)$ gene and replaces it with an equivalent, catalytically more efficient, thy $A$ gene. Both gene insertions were used to develop ribotype-specific PCRs, which were validated by screening a large strain collection consisting of 68 different PCR ribotypes supplemented with diverse 078 and 027 strains derived from different geographical locations and individual outbreaks. The genetic markers were stably present in the hypervirulent PCR ribotypes 078 and 027 , but were also found in several other PCR ribotypes. Comparative analysis of amplified fragment length polymorphisms, PCR ribotype banding patterns and toxin profiles showed that all PCR ribotypes sharing the same insert from phylogenetically coherent clusters. The identified loci are unique to these clusters, to which the hypervirulent ribotypes 078 and 027 belong. This provides valuable information on strains belonging to two distinct lineages within $C$. difficile that are highly related to hypervirulent strains.

\section{INTRODUCTION}

Clostridium difficile is a spore-producing anaerobic bacillus that resides in the gut, and has rapidly emerged as a leading cause of antibiotic-associated diarrhoeal disease in humans. Antibiotic treatments that suppress growth of the intestinal microbial flora, but spare $C$. difficile, allow this pathogen to colonize the gut. Upon colonization, $C$. difficile produces toxins that cause intestinal damage and inflammation, and consequently clinical disease (Kelly et al., 1994). Persistence of $C$. difficile in hospitals is enabled by humans shedding highly resistant and infectious spores (Rupnik et al., 2009). In the past decade, the incidence, complications and mortality of $C$. difficile-associated infections (CDIs) have increased dramatically due to the emergence of the hypervirulent strains PCR ribotypes 078 (NAP7/8) and 027 (NAP01) (Goorhuis et al., 2008; McDonald et al., 2005; Pépin et al.,

Abbreviations: AFLP, amplified fragment length polymorphism; CDI, C. difficile-associated infection; DHFR, dihydrofolate reductase; MLST, multilocus sequence typing.
2004, 2005). We define hypervirulent strains as those that are associated with more severe clinical disease. In addition to the production of toxin $\mathrm{A}(\mathrm{Tcd} A)$ and toxin $\mathrm{B}(\mathrm{TcdB})$, the presence of binary toxin ( $\mathrm{Cdt} A$ and $\mathrm{CdtB}$ ), altered antimicrobial resistance patterns and increased sporulation capacity can contribute to the virulence of certain $C$. difficile strains (Akerlund et al., 2008; Lyras et al., 2009; Merrigan et al., 2010; Schwan et al., 2009; Voth \& Ballard, 2005).

The virulence of $C$. difficile strains can be of importance when controlling infections. Although common infection control measures, such as good hygiene, cleaning of the patient environment and restricting antimicrobial therapy, are important in all cases of CDI, there are additional measures necessary to prevent the spread of certain PCR ribotypes; for example, restricting the use of fluoroquinolones to control CDI caused by the hypervirulent PCR ribotype 027 (Kallen et al., 2009; Warny et al., 2005). Therefore, it is important to identify which $C$. difficile strain is causing the infection at an early stage. 
C. difficile is a heterogeneous species, which can be typed based on various methods, including PCR ribotyping, amplified fragment length polymorphism (AFLP), multilocus sequence typing (MLST), multiple-locus variable number tandem repeat analysis (MLVA), toxinotyping, serotyping, repeat analysis and DNA microarrays (Bakker et al., 2010; Brazier, 2001; Griffiths et al., 2010; Killgore et al., 2008; Rupnik et al., 2001; Stabler et al., 2006). Currently, the most frequently used typing method in Europe is PCR ribotyping, which exploits the variability of the intergenic spacer region between the $16 \mathrm{~S}$ and $23 \mathrm{~S}$ rDNA. This variability, in combination with multiple copies of the rDNA, results in different amplicons after PCR amplification, which are referred to as PCR ribotypes (Bidet et al., 1999; Rupnik et al., 2009). Recently, PCR ribotyping was adapted to enable direct typing of $C$. difficile from stool samples (Janezic et al., 2011). Besides identification of the hypervirulent PCR ribotypes 078 and 027 , this method is currently capable of identifying over 300 different PCR ribotypes. PCR ribotyping depends on comparison of agarose/acrylamide gel patterns that requires standardization, a computer database containing each ribotype-specific pattern and computer-assisted analysis for correct interpretation. Occasionally, expertise is needed to interpret the generated PCR ribotype banding patterns. These requirements often limit interlaboratory reproducibility. Therefore, it would be very useful to identify genetic markers that can be used to develop a simple, robust and quick diagnostic method by which hypervirulent $C$. difficile strains are typed.

Comparative genome analysis has shown that $C$. difficile genomes are highly variable, which contributes to the distinct phenotypic differences (He et al., 2010; Sebaihia et al., 2006). The epidemic C. difficile 027 genome has 50 regions of genetic difference with a total of 234 additional genes compared with PCR ribotype 012 (Stabler et al., 2009). These variable regions can provide genetic markers for the identification of specific strains. A suitable marker should be stably integrated into the genome. However, many of the above-mentioned regions are not stably integrated, as they encode conjugative transposons or antibiotic resistance, or are sequences of phage origin that are involved in recombination, reshuffling or horizontal gene transfer (Sebaihia et al., 2006). These events make identification of stable strain-specific genetic markers challenging.

In this study we identified genetic markers that are stably present in the hypervirulent PCR ribotypes 078 and 027 and in closely related PCR ribotypes. Strains containing these markers represent specific lineages of $C$. difficile that are linked to hypervirulence.

\section{METHODS}

In silico comparison of full-length genomes. Whole genomes of PCR ribotypes 078 and 027 were compared with the PCR ribotype 012 genome using the National Center for Biotechnology Information (NCBI) BLAST application. The genomes of interest (PCR ribotypes
078 and 027) were translated by BLASTX and compared with a $C$. difficile protein database. This protein database, containing geneidentifier information for each ribotype together with corresponding protein sequences, was created by using the Choose Search Set functionality of BLASTX. By selecting C. difficile NAP08 (taxid: 525259) and C. difficile R20291 (taxid: 645463) the BLAST search was restricted to the sequences in the database from the organism that we selected. To discard genes that were abundantly present in the genome, we entered the following query into the Entrez query syntax: (NOT ribosomal[text] NOT rDNA[text] NOT tRNA[text] NOT polymerase [text] NOT rRNA[text] NOT transporter[text]). For genes that were likely to transfer to other genomes the following query was entered into the Entrez query syntax: (NOT gyrase[text] NOT tetracycline [definition] NOT transposon[text] NOT phage[text] NOT recombinase[text] NOT translocase[text] NOT conjugation[text]). A cut-off value of 1e-06 (E-value) was used to indicate a positive hit. Whenever a hit in protein sequence was found, the corresponding gene identifier was maintained. Next, we translated the genome of C. difficile 630 (PCR ribotype 012) with BLASTX using C. difficile NAP08 (taxid: 525259) or C. difficile R20291 (taxid: 645463) annotation. This was done to circumvent the problem of differences in gene annotation between $C$. difficile strains. This resulted in a second set of gene identifiers with annotation similar to that used for generating the first set. The two sets were compared and differences were selected as potential markers for the specific strains. An additional manual screen was performed on the markers found in order to discard genes that were not excluded by the initial query but still were likely to transfer to other genomes, for example any antibiotic-resistance gene. Then, we analysed the genomic region of the potential markers for the presence of genes associated with mobile elements. The presence of such genes in the vicinity of markers could indicate that they are not stably present and therefore potential markers associated with such genes were discarded. The remaining markers were screened for their uniqueness by performing a BLASTN and a BLASTP homology search of the selected region against all other sequenced $C$. difficile genomes (630 a.m.180355.1; CD196-FN538970.1; R20291-FN545816.1; 2007855FN665654.1; BI1-FN668941.1; M120-FN665653.1; BI9-FN668944.1; M68-FN668375.1; CF5-FN665652.1). Markers with no significant homology other than to the selected strain were considered the most promising. Finally, genome views were produced using the xBASE genome database (Chaudhuri et al., 2008).

PCR amplification. Purification of genomic DNA was performed by using the QIAamp DNA Blood Mini kit (Qiagen) according to the manufacturer's protocol. Part of the markers was amplified by PCR using 20 pmol forward and reverse primers (Table 1), 1 U GoTaq DNA polymerase (Promega) in $25 \mu \mathrm{l} 1 \times$ Green GoTaq Flexi Buffer PCR buffer (Promega), $0.2 \mathrm{mM}$ dNTPs and $3 \mathrm{mM} \mathrm{MgCl}_{2}$. The amplification was performed at $94{ }^{\circ} \mathrm{C}$ for $2 \mathrm{~min}, 30$ cycles of $95{ }^{\circ} \mathrm{C}$ for $30 \mathrm{~s}, 50{ }^{\circ} \mathrm{C}$ for $30 \mathrm{~s}$ and $72{ }^{\circ} \mathrm{C}$ for $30 \mathrm{~s}$, followed by a final extension at $72{ }^{\circ} \mathrm{C}$ for $10 \mathrm{~min}$. The PCR products were visualized by electrophoresis on an agarose gel $(1.5 \%)$ containing ethidium bromide.

Validation of PCR ribotype 078- and 027-specific markers. The presence of the specific markers was validated by screening 36 clinical isolates of ribotype 078 and 24 of ribotype 027 originating from various geographical locations and times. In addition, a library of 68 unique representative PCR ribotypes (Leeds-Leiden collection), including the 20 most frequently found PCR ribotypes in The Netherlands, was screened for the presence of the genetic markers. This library was validated (i.e. confirmation of the PCR ribotype) by several specialized laboratories in Europe and Canada. If other PCR ribotypes were found to be positive for the insert, additional strains from these PCR ribotypes were screened. PCR products obtained from several PCR ribotypes were sequenced to confirm amplification of the intended regions. 
Table 1. Primers used for the PCRs developed and for AFLP

\begin{tabular}{|lccl|}
\hline Primer & Product size $(\mathbf{n t})$ & Target(s) & \multicolumn{1}{c|}{ Sequence $\left(\mathbf{5}^{\prime} \rightarrow \mathbf{3}^{\prime}\right)^{*}$} \\
\hline $\begin{array}{l}\text { PCR } \\
\text { 078_insert }\end{array}$ & 707 & ZP_05399691, ZP_05399692, ZP_05399693 & Fw, AAAGGAACAGCCTAGGGAAC \\
027_insert & 691 & CDR20291_0045 & Rv, TGGGACTGGAGATTATGG \\
AFLP & & & Fw, TGGCTCAGAGGTAGTTGCTGCG \\
Pst-0 & - & Pst I adaptor & GACTGCGTACATGCAG \\
Mse-C & - & $M s e I$ adaptor & GATGAGTCCTGAGTAAC \\
\hline
\end{tabular}

${ }^{\star} \mathrm{Fw}$, forward; Rv, reverse.

Genetic similarity analysis. AFLP was performed as previously described (Killgore et al., 2008). Briefly, whole genomic DNA was restricted with two enzymes (PstI and MseI), followed by ligation of two corresponding adapters (PstI and MseI adaptor) to the restriction sites. Then, the Pst-0 and Mse-C primers (Table 1) were used to amplify the PstI- and MseI-tagged fragments. One selective nucleotide (Mse-C) was introduced to reduce the complexity of the amplified AFLP pattern. Pst-0 was fluorescently labelled with carboxyfluorescein (Eurogentec). Analysis of the amplification was done on an ABI Prism 3130 capillary sequencer. The resulting DNA patterns were compared using the Bionumerics software package, version 3.0 (Applied Maths). Similarity coefficients were calculated with Pearson correlation and dendrograms were created by the unweighted pair group method using arithmetic averages (UPGMA) clustering.

PCR ribotyping was performed as described by Bidet et al. (1999). Dendrograms of PCR ribotype amplification profiles were used to analyse genetic similarity. Similarity coefficients were calculated with Pearson correlation and dendrograms were created with Bionumerics software version 6.01 (Applied Maths) using curve-based clustering. The presence of the genes $t c d A, t c d B$ and $c d t A$, and possible deletions in the $t c d C$ gene, were detected by PCR as described elsewhere and were used to study genetic similarity (Alonso et al., 1999; Kato et al., 1999; Spigaglia \& Mastrantonio, 2002).

Incidence data and patient characteristics. The prevalence of various PCR ribotypes was determined using the database of the Dutch Reference Laboratory. All isolates submitted $(n=4383)$ to this laboratory between January 2005 and December 2010 were included in the database and were derived from patients with diarrhoea. To investigate the type-specific course of CDIs with sufficient power, we used the dataset of a recent pan-European study (Bauer et al., 2011) combined with the dataset of a 3-year incidence study in which all patients with diarrhoea and a positive toxin test from 13 hospitals in The Netherlands were included (unpublished results). Three months after the diagnosis, survival status was determined (total $n=1026$ patients). We compared the 90-day mortality rate between patients with CDI due to PCR ribotype 078, 078-like, 027 and 027-like strains and other PCR ribotypes by means of Fisher's exact test. PASW 17.0.2 (SPSS) software was used for statistical analyses.

\section{RESULTS}

\section{Identification of inserts specific for $C$. difficile PCR ribotypes 078 and 027}

Whole genome sequencing of various PCR ribotypes revealed 4.1-4.3 Mb chromosomes with a mosaic of mobile elements (He et al., 2010). Matching up the genome of reference strain 630 (PCR ribotype 012) with PCR ribotype 078 and 027 strains (see Methods) revealed several potentially distinctive markers, including (parts of) transposable elements (Sebaihia et al., 2006), sequences of phage origin (defined by BLAST hits in clostridium phages) and CRISPRs (clustered regularly interspaced short palindromic repeats)-associated proteins (annotated in 078 strain $C$. difficile QCD-23m63). The above-mentioned markers and several other inserts encoding genes involved in recombination were discarded. Of the remaining markers, we selected the regions with no significant homology other than to the strain of interest (PCR ribotype 078 and 027 strains) as the most promising markers. As a result, we identified two potentially unique inserts, one present in PCR ribotype 078 and the other present in PCR ribotype 027. Fig. 1(a) shows the result of a BLAST nucleotide database search of the selected 078 and 027 regions, including flanking regions. The flanking regions show good alignment with all full-length sequenced C. difficile strains, whereas the unique inserts are only found in the corresponding ribotype, 078 (M120 strain) and 027 (R20291;BI1;CD196;2007855 strains), respectively.

\section{Characterization of PCR ribotype 078- and 027- specific inserts}

The region selected for PCR ribotype 078 is 1675 bp long and contains three ORFs (see Fig. 1b, Table 2). The insertion of the 078 locus is precisely in the intergenic region between guaA (GMP synthase) and a putative nucleotidase (CD0198 and CD0199, respectively; annotation according to reference strain 630). Homology searches in the NCBI protein database revealed that the first predicted ORF of the 078 insert, ZP_05399691, has high sequence identity to proteins encoded by a Gram-negative sulphate-reducing bacterium, Desulfovibrio fructosovorans (E-value 3e-37, and data not shown). Profile analysis of protein sequences (Söding, 2005) showed that ZP_05399691 belongs to a family of antibiotic biosynthesis monooxygenases (E-value 0.0019; PFAM03992) involved in the biosynthesis of several antibiotics (Sciara et al., 2003). Profile analysis of the predicted ORF ZP_05399692 did not produce significant 
(a)
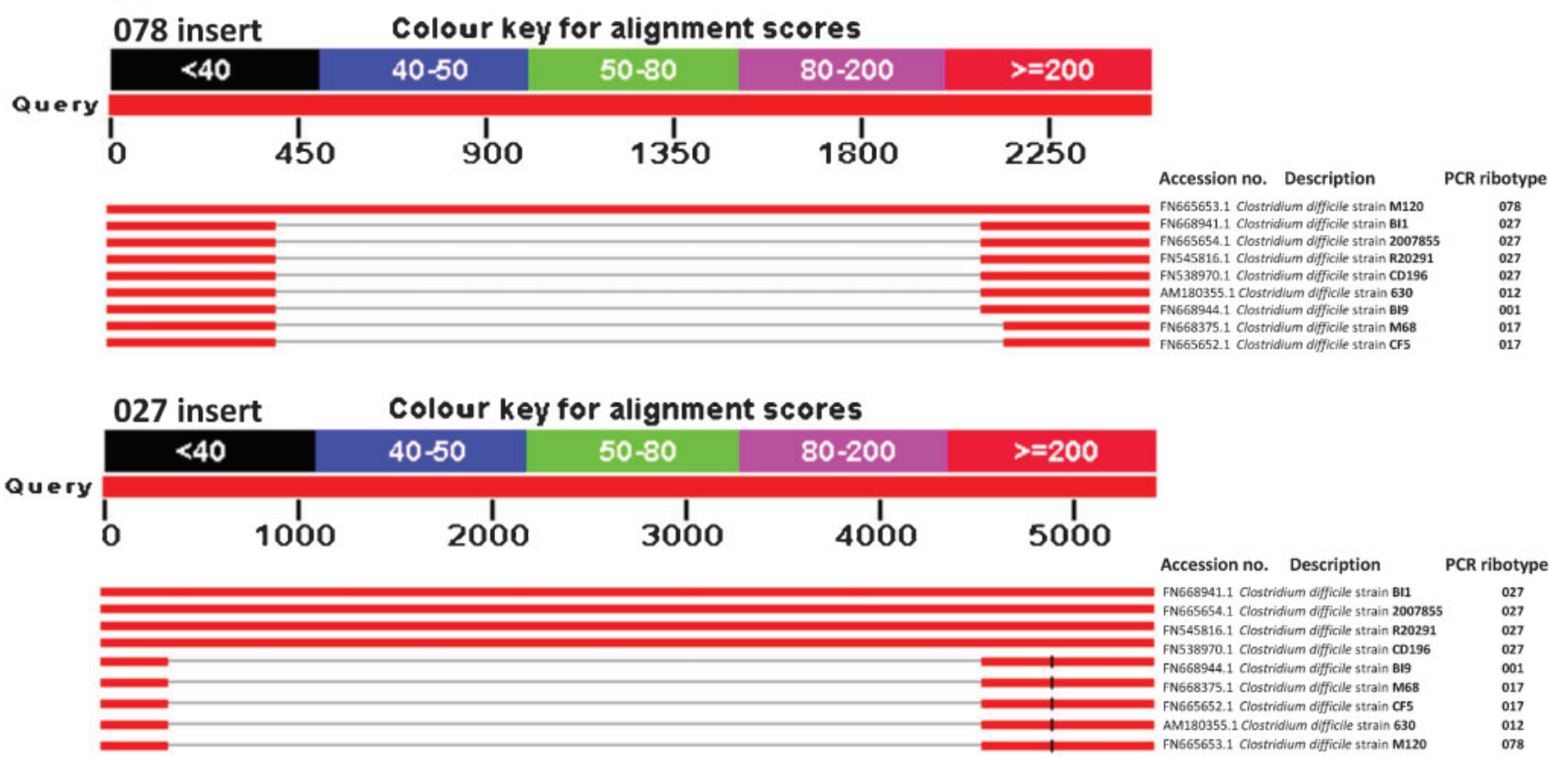

(b)

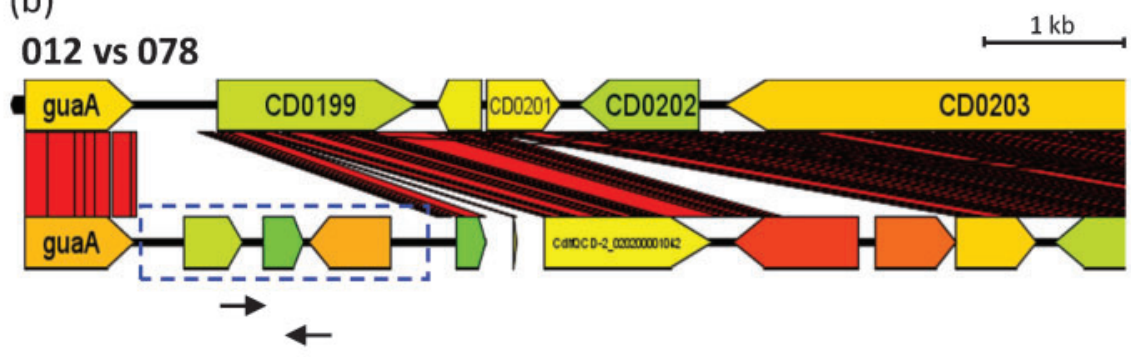

012 vs 027

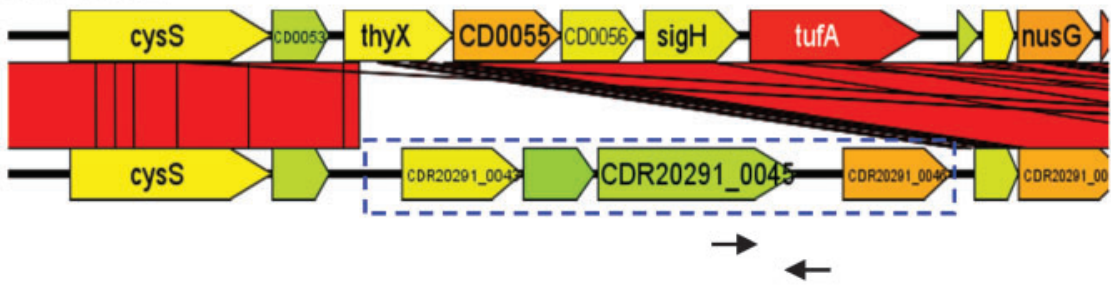

Fig. 1. In silico identification of unique inserts for $C$. difficile PCR ribotypes 078 and 027. (a) Result of BLASTN homology search of region 249 237-250912 of C. difficile ribotype 078 strain M120 (GenBank/EMBL/DDBJ accession no. FN665653.1) and region 80832-84988 of C. difficile ribotype 027 strain R20291 (accession no. FN545816.1) including the 300-500 nt flanking region. The resulting graphic summary is shown. (b) Pairwise comparisons between PCR ribotype 012 (630) and 078 (top) and between 012 and 027 (bottom). Shown are diagrammatic representations of the genes surrounding the inserts using the web-based database xBASE (colour based on percentage DNA G + C content). The blue dashed box indicates the inserted region and arrows indicate the PCR primers used for amplification; bar, $1 \mathrm{~kb}$ size marker.

hits (data not shown), whereas BLASTP analysis of the ORF ZP_05399693 resulted in a GCN5-acetyltransferase as the closest homologue. It should be noted that an isolated transposase-like protein $\mathrm{B}$ is situated $1.4 \mathrm{~kb}$ downstream of the 078 insert, and is not part of the insert itself.
The PCR ribotype 027 insert is $4156 \mathrm{bp}$ long and contains four ORFs (see Fig. 1b, Table 2). Unlike the 078 insert, the 027 insert disrupts the thy $X$ gene (flavin-dependent thymidylate synthetase), in which it has inserted (see Fig. 1b). The first two ORFs (CDR20291_0043 and CDR20291_0044) of 
Table 2. General description of the 078 and 027 inserts

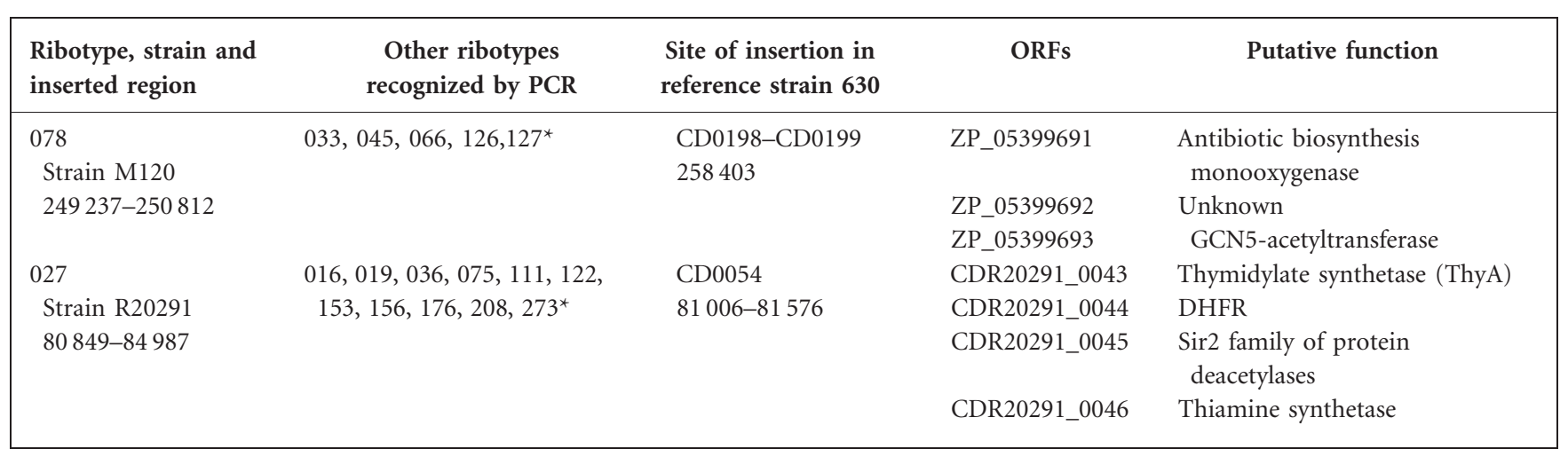

${ }^{*}$ ORFs of the ribotype 078 and 027 inserts described in this paper (078 strains M120 and C. difficile QCD-23m63; 027 strain R20291).

the 027 insert encode the enzymes thymidylate synthetase A (ThyA) and dihydrofolate reductase (DHFR), both of which are involved in the biosynthesis of the DNA base thymine (dTMP). The third ORF (CDR20291_0045) has homology to the Sir2 family of protein deacetylases (E-value 2.2e-26). The last ORF encodes the thiamine biosynthesis protein ThiC (CDR20291_0046).

The insertion of the 027 region into the gene encoding ThyX has resulted in a non-functional thy $X$ gene, which is subjected to accumulation of mutations. The relative age of this non-functional gene is reflected in its number of such mutations. Compared with PCR ribotype 012, containing a functional thyX, 38 mutations have occurred in this gene (540 nt). With an estimated synonymous mutation rate of 0.0002 per genome/per generation in $C$. difficile (note: including functional ORFs) (He et al., 2010), it is clear that the 027 insert occurred early in the Clostridium lineage and has been present ever since.

\section{Validation of PCR ribotype 078- and 027-specific inserts}

To confirm the uniqueness of the 078/027-specific inserts, we developed a PCR with a primer pair amplifying part of the insert (see Methods). Sixty-eight representative strains from a validated PCR ribotype library (collaboration of University of Leeds and University of Leiden) were analysed for the presence of the 078- and 027-specific inserts. Surprisingly, although 63 tested negative for the presence of the 078-specific region, four other PCR ribotypes showed a PCR amplification product (see Fig. 2a). Positive for the 078 insert were PCR ribotypes 033, 045, 066, 078 and 126. To confirm these results we used the database of the reference laboratory of the Leiden University Medical Center for $C$. difficile to select additional isolates for these respective ribotypes obtained from various geographical locations and outbreaks. Seven PCR ribotype 033, 11 PCR ribotype 045, one PCR ribotype 066, 32 PCR ribotype 078 and nine PCR ribotype 126 strains were tested. In addition, we included a strain belonging to PCR ribotype 127 in our analysis, as this ribotype has a banding pattern similar to that of PCR ribotype 078 (see Fig. 4, below). All these isolates, including several animal strains, tested positive for the presence of the 078 marker (see Fig. 2c, and data not shown).

We also tested our PCR ribotype library for the presence of ribotypes containing the 027 region. As shown in Fig. 2(b), besides PCR ribotype 027 , PCR ribotypes 016, 036, 075, 122 and 153 contained the 027 -specific region, as evidenced by the presence of a PCR amplicon. The presence of the 027 region in these PCR ribotypes was confirmed by testing additional isolates. Four PCR ribotype 016, three PCR ribotype 036, four PCR ribotype 075, four PCR ribotype 153, one PCR ribotype 122 and 24 PCR ribotype 027 strains were tested. In addition, we supplemented our collection with strains belonging to PCR ribotypes 019,111 and 156, as two recent studies have indicated that these types are closely related to PCR ribotype 027 (Griffiths et al., 2010; Zaiss et al., 2009). Furthermore, we included three strains belonging to PCR ribotypes 176, 208 and 273, which have PCR ribotype patterns similar to that of PCR ribotype 027 (see Fig. 4 below). All these strains tested positive in our PCR for the presence of the 027 marker (see Fig. 2d, and data not shown). In summary, after screening a large collection of different PCR ribotypes, we found that the 078 and 027 inserts are also present in several other PCR ribotypes.

\section{Comparative analyses of strains containing the genetic marker}

The presence of the 078 and 027 markers in several PCR ribotypes suggests that a common ancestor had these respective inserts. Potential relationships among these strains were examined through cluster analysis (see Methods) of AFLP patterns and PCR ribotype banding patterns. The AFLP patterns generated are presented in a dendrogram (Fig. 3). Strains positive for the 078 and 027 markers had similar profiles and evidently clustered together into distinct groups with a relative similarity of approximately $85 \%$ (Fig. 3, blue for the 027 group, green for the 078 group), corresponding to the recommended 
(a)
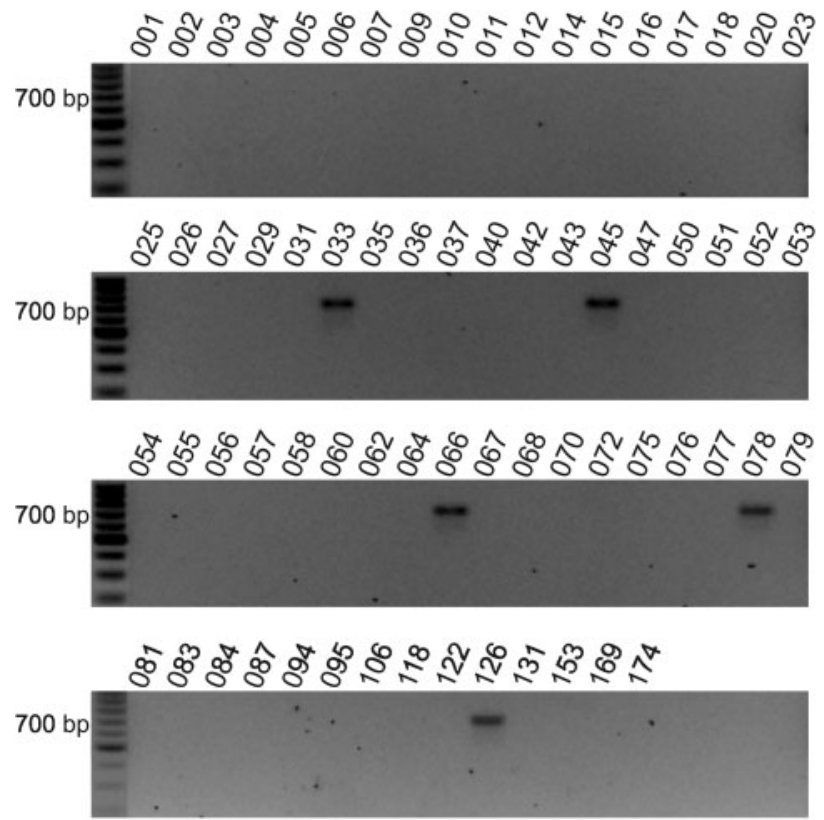

(c)

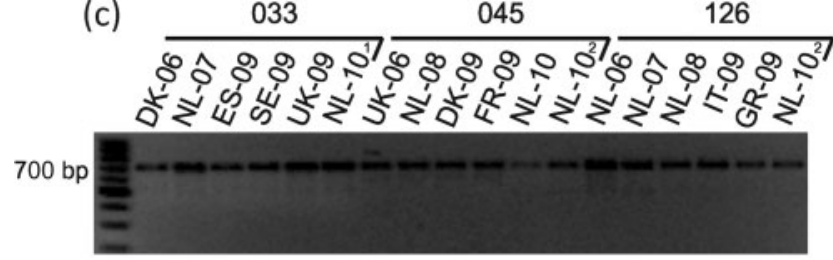

(d)

027

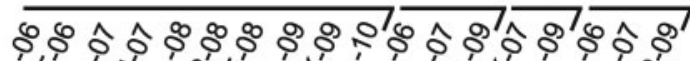
0
0.00
0

$700 \mathrm{bp}=$

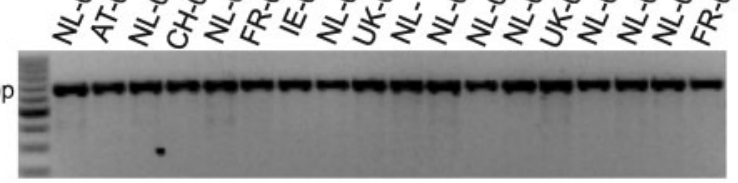

(b)

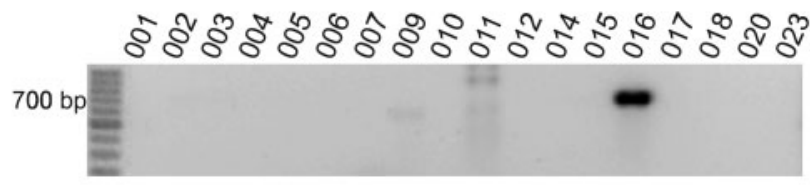

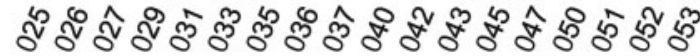

$700 \mathrm{bp}$ 를

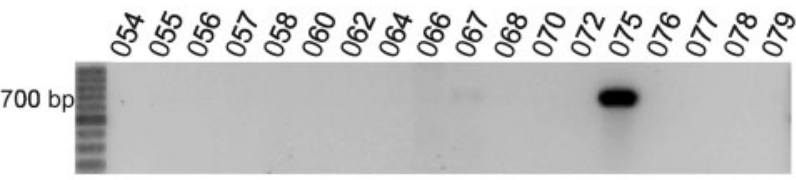

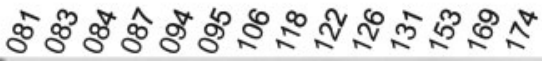

$700 \mathrm{bp}$
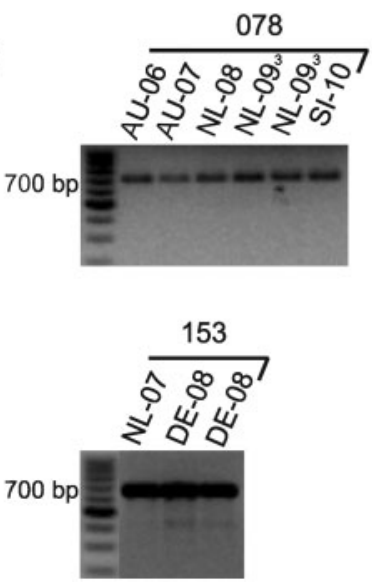

Fig. 2. Presence of 078 and 027 markers in a large PCR ribotype strain collection. (a, b) Results from PCR amplification of the 078 insert (a) and the 027 insert (b) performed on isolates representing various PCR ribotypes, as indicated by the numbers above the lanes. (c) Diverse isolates from humans and animals belonging to PCR ribotypes 033, 045, 126 and 078 were tested for the 078 insert. Two-letter country codes, followed by the year of isolation, indicate the geographical location of the clinical isolate. Small numbers above the isolation year indicate isolation from a source other than humans, i.e. cow (1), horse (2) and pig (3). (d) Diverse isolates belonging to PCR ribotypes 027, 016, 036, 075 and 153 were tested for the 027 insert. Lane identification by numbers refers to ribotype number. The left-hand lane of each panel contains a size marker in 100 bp steps (Roche Diagnostics). PCR products were separated on a $1.5 \%(\mathrm{w} / \mathrm{v})$ agarose gel.

cut-off value used for the identification of identical strains (Killgore et al., 2008). As for the AFLP patterns, we presented the generated ribotype banding patterns in a dendrogram (Fig. 4). Strains positive for the 078 marker clustered together in a distinct group (relative similarity $>85 \%)$. Strains positive for the 027 marker also clustered together in a single group, with only PCR ribotype 156 showing a divergent pattern. Thus, our markers for 078 and 027 recognize PCR ribotypes that are clustered in distinct and genetically related groups, supporting the use of these inserts to identify these '078-like' and '027-like' types.

To further study potential relationships among the 078-like and 027-like strains, we analysed the toxin profiles (Table 3 ). All strains in the 078-like group, with the exception of one strain belonging to PCR ribotype 033 , were positive for toxin $\mathrm{A}(t c d A)$, toxin $\mathrm{B}(t c d B)$ and binary toxin $(c d t A)$. The 


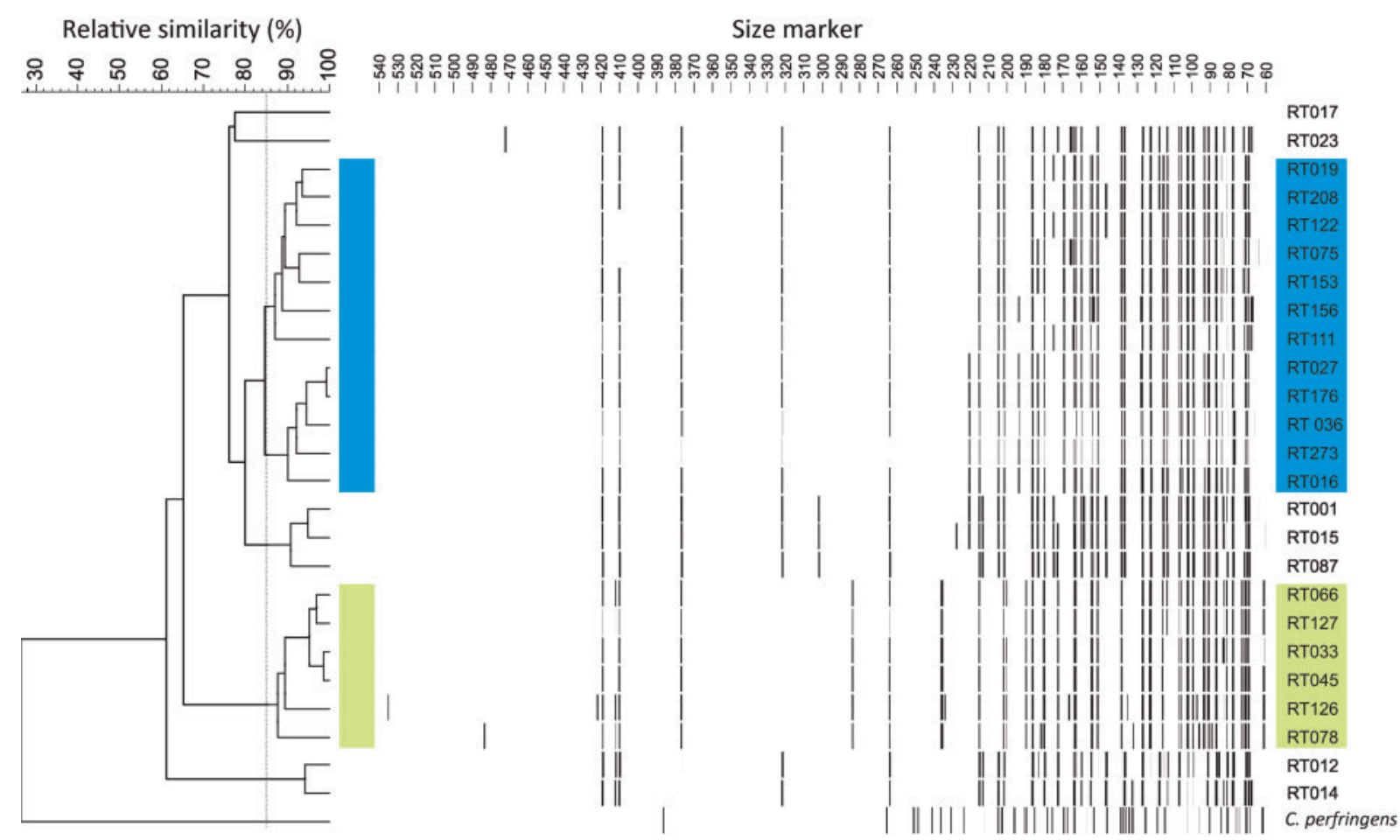

Fig. 3. Dendrogram of $C$. difficile strains based on AFLP patterns, illustrating the clustering of strains positive for the 078 (green) and 027 markers (blue). Hierarchical clustering of AFLP types was established by the Bionumerics software package (Applied Maths) using unweighted pair-grouping (see Methods). The cut-off value for identification of identical strains was set at $85 \%$ relative similarity. Clostridium perfringens was included as a control at the species level.

PCR ribotype 033 strain was negative for $t c d B$. Others have shown that PCR ribotype 033 can also be positive for $t c d B$ (Pituch et al., 2006). In addition, all strains in the 078-like group possessed the $39 \mathrm{bp} t c d C$ deletion, which is a distinct marker for PCR ribotype 078 (Goorhuis et al., 2008), supporting the notion that these strains are closely related. All strains in the 027-like group were positive for $t c d A, t c d B$ and $c d t A$, with the exception of a PCR ribotype 208 strain, which was negative for $c d t A$. Furthermore, we observed heterogeneity for the presence of the $18 \mathrm{bp} t c d C$ deletion within the 027-like group, as reported by another group (Janvilisri et al., 2009).

Next, we analysed the prevalence of PCR ribotypes that were positive for the 078/027 insert. Hypervirulent strains 078 and 027 comprise 10 and $11 \%$ of the total number of samples $(n=4383)$ submitted to the Dutch National Reference Laboratory, respectively (Fig. 4). All other types tested were less frequently found $(<1.3 \%)$. Although 078 like and 027-like strains are only found sporadically, we analysed whether these strains were as hypervirulent as their counterparts, based on the number of deaths after 90 days. Mortality in patients with CDI due to PCR ribotype 078 and 078 -like was $26 \%$ (28/104) and $27 \%$ (7/ 26 ), respectively, after 90 days, higher than in patients who suffered from CDI due to other ribotypes $(20 \%, 166 / 812)$. This difference, however, was not statistically significant
( $P=0.13$ and $P=0.46$, respectively). Mortality in patients with CDI due to type 027 and $027-$ like was $34 \%(24 / 70)$ and $29 \%(4 / 14)$, respectively, after 90 days. Mortality in patients with CDI due to PCR ribotype 027 was significantly higher than that in patients with CDI due to other types $(P=0.01)$. Patients with CDI due to ribotype 027-like also showed higher mortality than patients with CDI due to other types, although the difference was not significant $(P=0.50)$.

\section{DISCUSSION}

Gene transfer between different species allows bacteria to acquire new traits, potentially conferring evolutionary adaptations to the selective conditions encountered. We have exploited these genes, aiming to develop specific PCRs for identification of the two C. difficile hypervirulent PCR ribotypes 078 and 027 . We have identified genetic markers for these hypervirulent PCR ribotypes and closely related PCR ribotypes. The 078 and 027 insertions are not part of a module involved in conjugation or excision (Sebaihia et al., 2006) and are probably stably integrated, as is exemplified by their presence in 078/027 strains collected from different outbreaks throughout the world (14 European countries and Australia) over a period of 4 years (between 2006 and 2010). 


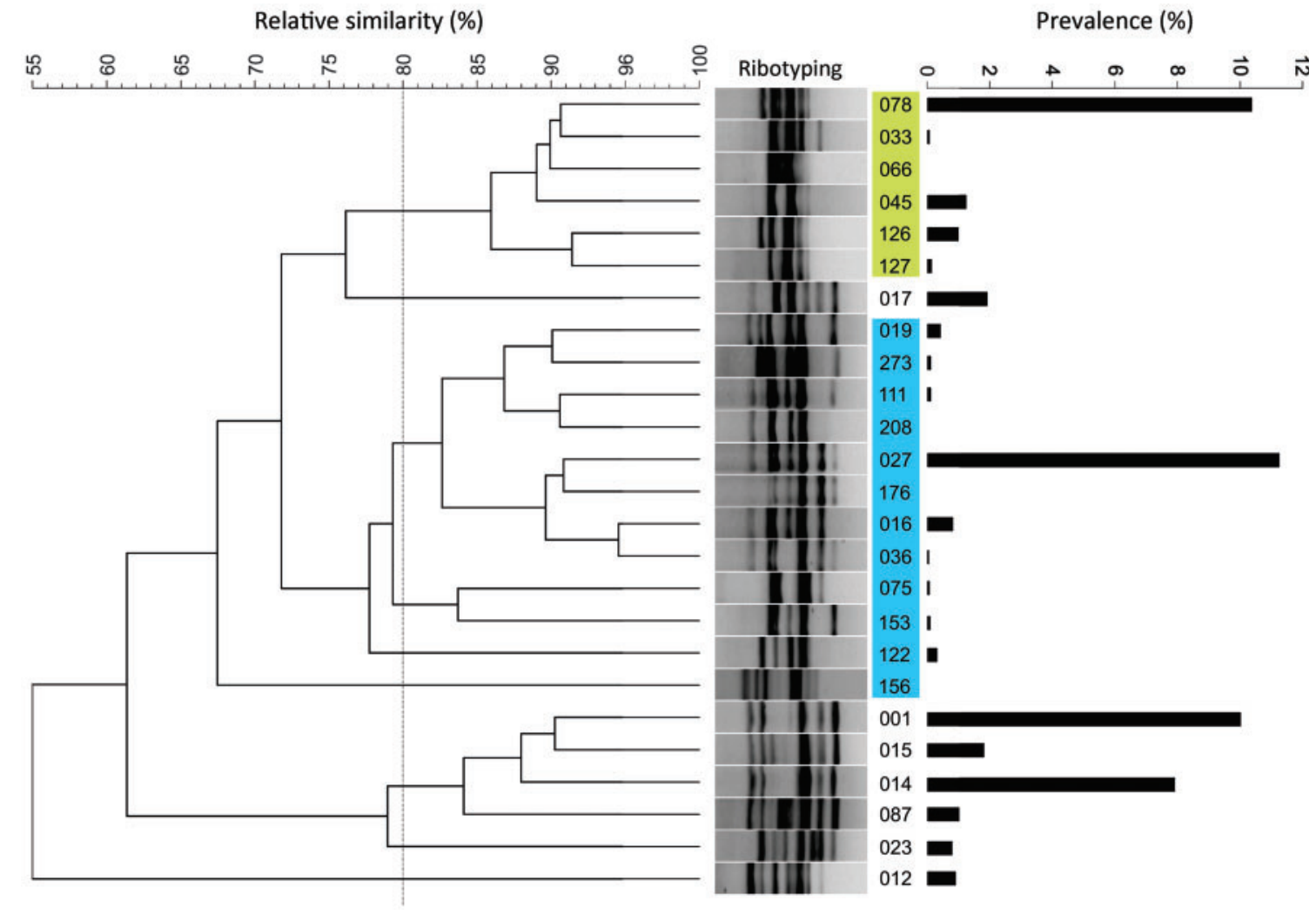

Fig. 4. Dendrogram of $C$. difficile strains based on PCR ribotype, illustrating the clustering of strains positive for the 078 and 027 markers. Hierarchical clustering of PCR ribotypes was established by the Bionumerics software package (Applied Maths) using curve-based clustering (see Methods). Prevalence (belonging to the strains positive for our markers) was calculated over a total of 1552 strains that were collected in a period between January 2009 and August 2010. Similar colours were used to illustrate clustering according to AFLP patterns. The cut-off value for identifying clusters was set at $80 \%$ relative similarity.

Comparative analyses show that the PCR ribotypes with the 078 insert $(033,045,066,078,126$ and 127) form a phylogenetically coherent group, which is reflected by similarities in AFLP patterns, similarities in ribotype patterns, presence of the binary toxin gene $c d t A$ and the presence of the characteristic $t c d C$ deletion (39 bp). Similarly, the PCR ribotypes with the 027 insert (016, 019, 027, 036, 075, 111, 122, 153, 156, 176, 208 and 273) are also closely related to each other, which is confirmed by clustering of the AFLP patterns into a distinct group, similarities in ribotype patterns and the presence of $c d t A$. PCR ribotypes 078 and 027 are the most prevalent types in their cluster, while the 078-like and 027-like strains are found in low numbers among humans (Fig. 4).

Clearly, the presence of a unique insert within seemingly diverse PCR ribotypes suggests that they share a common ancestor. Complementary to our comparative analysis, sequence analysis of the $16 \mathrm{~S}$ rRNA genes of ribotypes 033 , 045, 066 and 078 has shown that they all contain a unique base change compared with other strains, confirming that they represent a well-defined subpopulation within the $C$. difficile species (Rupnik et al., 2001). In the past few years it has become clear that $C$. difficile has also emerged as an animal pathogen. The PCR ribotype most prominently present in farm animals is 078 , accounting for more than $90 \%$ of porcine and bovine isolates (Keel et al., 2007; Weese et al., 2010). Overlap between 078 isolates from animals and humans led to the hypothesis of a zoonotic transmission route (Bakker et al., 2010), but this awaits confirmation. Other ribotypes found in livestock are 002, 033, 045, 066, 077 and 126 (Avbersek et al., 2009; Keel et al., 2007; Pirs et al., 2008). Except for 002 and 077, all these ribotypes tested positive in our 078 PCR, representing more than $95 \%$ of the species found in livestock. This indicates that the 078 marker can be used for typing 078 and 078-like strains.

Our comparative analysis shows that the PCR ribotypes with the 027 marker are closely related to each other. Clustering of the PCR ribotype group 027 has been partially confirmed by two other research groups (see Table 3). Griffiths et al. (2010) identified a phylogenetically coherent group of $C$. difficile strains using MLST. This group, which was marked as hypervirulent, consists of PCR ribotypes 027, 019, 036 and 153. In addition, Zaiss et al. 
Table 3. Molecular characterization of the C. difficile lineages 078 and 027

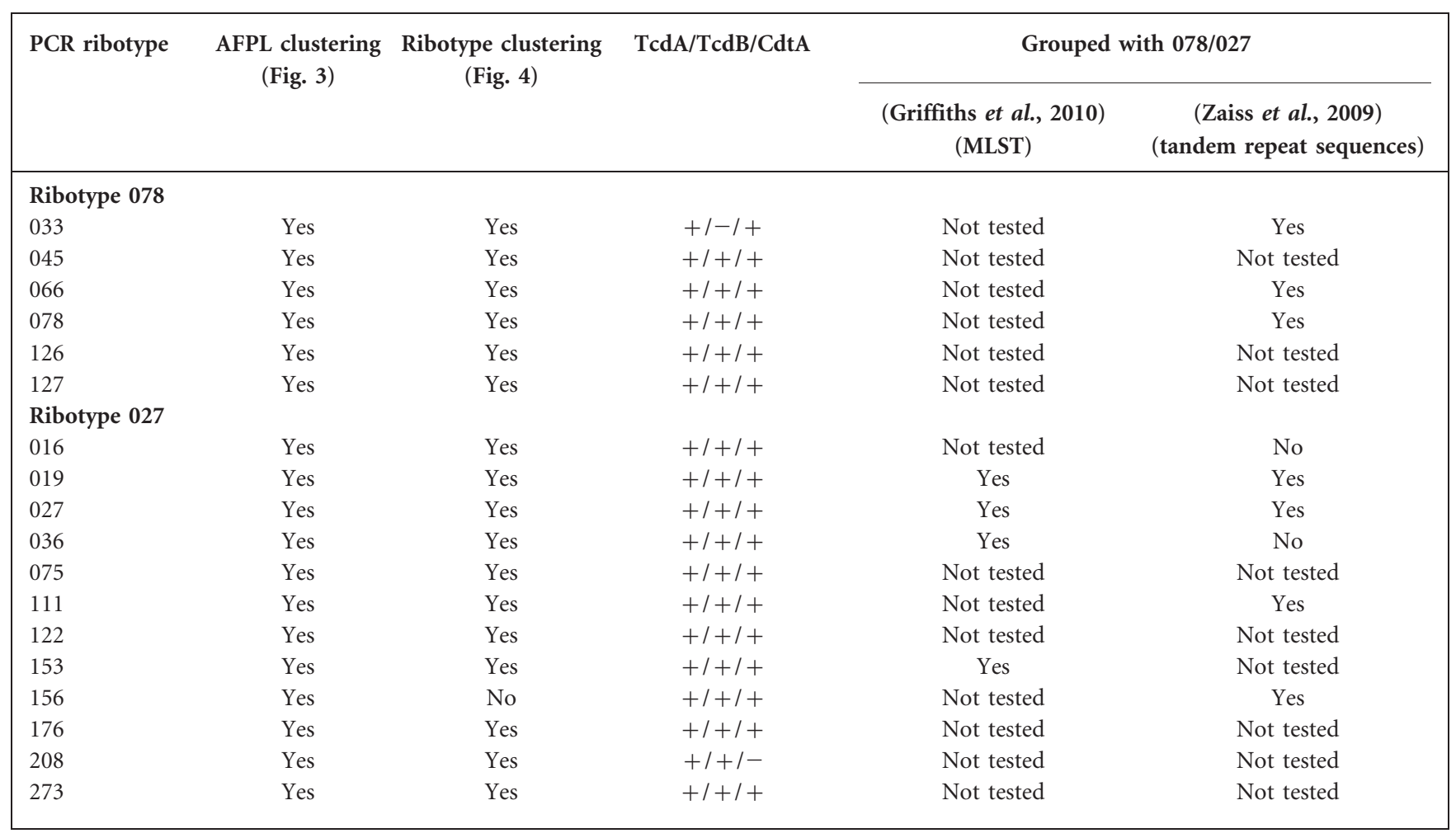

(2009) performed typing of $C$. difficile based on tandem repeat sequences. In their study, PCR ribotype 027 clustered together with ribotypes 019,111 and 156 into a distinct group. These data, which correlate with our own, confirm that the 027 marker identified in this study can be used to recognize PCR ribotype 027 and 027-like strains. Finally, the 027 genetic marker is noted in a microarray study by Marsden et al. (2010), where it was reported that this insert of four genes is present in PCR ribotypes 001, 027, 078 and 106. Our results and in silico genome comparisons (see Figs 1a and 2) clearly show that the insert is present in PCR ribotype 027 but not in PCR ribotypes 001, 078 or 106.

Rapid and reliable identification of $C$. difficile types is necessary for controlling CDI. A novel typing method based on the described markers has some limitations when compared with other typing methods such as PCR ribotyping. The presence of the markers in strains other than the hypervirulent PCR ribotypes 078 and 027 reduces its discriminatory power. Nevertheless, the markers can be useful in a rapid pre-screen for detecting potentially hypervirulent strains, especially when considering that the hypervirulent strains are the most prevalent strains of their lineages and that the other strains are much less frequently found. The result of the newly proposed pre-screen is easy to interpret, i.e. marker present or not present, and therefore no expertise or software and databases are required to perform it. This makes it suitable for use in clinical laboratories worldwide. In addition, use of the markers can provide the user with additional information on relatedness between strains, as it is capable of identifying hypervirulent PCR ribotypes 078 and 027 and closely related ribotypes with possibly similar virulence potential. This additional information may be of interest when taking into account how new PCR ribotypes can arise. New PCR ribotypes are assigned when a ribotype pattern is found which differs by at least one band from already defined types. Recently, it has been shown that mechanisms such as homologous recombination (Dingle et al., 2011) or slippedstrand mispairing during DNA replication can be responsible for variation in the intergenic spacer region (Indra et al., 2010). Such events make it plausible that newly identified PCR ribotypes will arise from hypervirulent $C$. difficile strains, and these may share virulence potential and clinical manifestations.

Analysis of the genes that are located on the 078 and 027 inserts could elucidate the potential impact of the insert on the phenotype. One of the ORFs present on the 078 insert belongs to a family of genes that are involved in biosynthesis of several antibiotics, which might confer a competitive advantage upon PCR ribotype 078.

Insertion of the 027 marker in thyX causes disruption of this gene (see Fig. 1b). At first this seems puzzling, as thy $X$ is an essential gene required for biosynthesis of dTMP. Its important role in microbial DNA replication and presence in several pathogenic bacteria makes it an attractive potential target for antibiotic drug development (Esra Önen et al., 2008; Koehn et al., 2009). Remarkably, the 
027 insert replaces ThyX by a different, although functionally equivalent, enzyme, thymidylate synthetase A (ThyA), together with an additional enzyme, dihydrofolate reductase (DHFR) (see Table 2). The two thymidylate synthetases use different mechanisms in the biosynthesis of dTMP (Koehn et al., 2009). In contrast to ThyX, which produces tetrahydrofolate (THF), ThyA forms dihydrofolate (DHF) and requires DHFR to produce THF (Koehn \& Kohen, 2010). It has been shown that the ThyA enzyme is catalytically more efficient than the ThyX enzyme (Escartin et al., 2008), and consequently microbes that contain the highly active ThyA could have a growth advantage. Growth curve analysis with isogenic strains containing either gene (thy $X$ or thy $A$ together with DHFR) should clarify whether there is a difference in growth rate.

This study provides a comprehensive overview of the genetic lineages of $C$. difficile that are related to hypervirulent PCR ribotypes 078 and 027 . PCR analysis of the genetic markers provides a rapid and easy way to type the hypervirulent PCR ribotypes 078 and 027 and closely related PCR ribotypes, irrespective of host and geographical location.

\section{ACKNOWLEDGEMENTS}

This work was supported by The Netherlands Organization for Scientific Research (NWO) (ZonMw grant 50-50800-98-079) and HYPERDIFF-The Physiological Basis of Hypervirulence in Clostridium difficile: a Prerequisite for Effective Infection Control (Health-F3-2008223585).

\section{REFERENCES}

Akerlund, T., Persson, I., Unemo, M., Norén, T., Svenungsson, B., Wult, M. \& Burman, L. G. (2008). Increased sporulation rate of epidemic Clostridium difficile type 027/NAP1. J Clin Microbiol 46, 1530-1533.

Alonso, R., Muñoz, C., Gros, S., García de Viedma, D., Peláez, T. \& Bouza, E. (1999). Rapid detection of toxigenic Clostridium difficile from stool samples by a nested PCR of toxin B gene. J Hosp Infect 41, 145-149.

Avbersek, J., Janezic, S., Pate, M., Rupnik, M., Zidaric, V., Logar, K., Vengust, M., Zemljic, M., Pirs, T. \& Ocepek, M. (2009). Diversity of Clostridium difficile in pigs and other animals in Slovenia. Anaerobe 15, 252-255.

Bakker, D., Corver, J., Harmanus, C., Goorhuis, A., Keessen, E. C., Fawley, W. N., Wilcox, M. H. \& Kuijper, E. J. (2010). Relatedness of human and animal Clostridium difficile PCR ribotype 078 isolates determined on the basis of multilocus variable-number tandem-repeat analysis and tetracycline resistance. J Clin Microbiol 48, 3744-3749.

Bauer, M. P., Notermans, D. W., van Benthem, B. H., Brazier, J. S., Wilcox, M. H., Rupnik, M., Monnet, D. L., van Dissel, J. T., Kuijper, E. J. \& ECDIS Study Group (2011). Clostridium difficile infection in Europe: a hospital-based survey. Lancet 377, 63-73.

Bidet, P., Barbut, F., Lalande, V., Burghoffer, B. \& Petit, J. C. (1999). Development of a new PCR-ribotyping method for Clostridium difficile based on ribosomal RNA gene sequencing. FEMS Microbiol Lett 175, 261-266.

Brazier, J. S. (2001). Typing of Clostridium difficile. Clin Microbiol Infect 7, 428-431.
Chaudhuri, R. R., Loman, N. J., Snyder, L. A., Bailey, C. M., Stekel, D. J. \& Pallen, M. J. (2008). xBASE2: a comprehensive resource for comparative bacterial genomics. Nucleic Acids Res 36 (Database issue), D543-D546.

Dingle, K. E., Griffiths, D., Didelot, X., Evans, J., Vaughan, A., Kachrimanidou, M., Stoesser, N., Jolley, K. A., Golubchik, T. \& other authors (2011). Clinical Clostridium difficile: clonality and pathogenicity locus diversity. PLoS ONE 6, e19993.

Escartin, F., Skouloubris, S., Liebl, U. \& Myllykallio, H. (2008). Flavindependent thymidylate synthase $\mathrm{X}$ limits chromosomal DNA replication. Proc Natl Acad Sci U S A 105, 9948-9952.

Esra Önen, F., Boum, Y., Jacquement, C., Spanedda, M. V., Jaber, N., Scherman, D., Myllykallio, H. \& Herscovici, J. (2008). Design, synthesis and evaluation of potent thymidylate synthase $\mathrm{X}$ inhibitors. Bioorg Med Chem Lett 18, 3628-3631.

Goorhuis, A., Bakker, D., Corver, J., Debast, S. B., Harmanus, C., Notermans, D. W., Bergwerff, A. A., Dekker, F. W. \& Kuijper, E. J. (2008). Emergence of Clostridium difficile infection due to a new hypervirulent strain, polymerase chain reaction ribotype 078. Clin Infect Dis 47, 1162-1170.

Griffiths, D., Fawley, W., Kachrimanidou, M., Bowden, R., Crook, D. W., Fung, R., Golubchik, T., Harding, R. M., Jeffery, K. J. \& other authors (2010). Multilocus sequence typing of Clostridium difficile. J Clin Microbiol 48, 770-778.

He, M., Sebaihia, M., Lawley, T. D., Stabler, R. A., Dawson, L. F., Martin, M. J., Holt, K. E., Seth-Smith, H. M., Quail, M. A. \& other authors (2010). Evolutionary dynamics of Clostridium difficile over short and long time scales. Proc Natl Acad Sci U S A 107, 7527-7532.

Indra, A., Blaschitz, M., Kernbichler, S., Reischl, U., Wewalka, G. \& Allerberger, F. (2010). Mechanisms behind variation in the Clostridium difficile 16S-23S rRNA intergenic spacer region. J Med Microbiol 59, 1317-1323.

Janezic, S., Strumbelj, I. \& Rupnik, M. (2011). Use of modified PCR ribotyping for direct detection of Clostridium difficile ribotypes in stool samples. J Clin Microbiol 49, 3024-3025.

Janvilisri, T., Scaria, J., Thompson, A. D., Nicholson, A., Limbago, B. M., Arroyo, L. G., Songer, J. G., Gröhn, Y. T. \& Chang, Y. F. (2009). Microarray identification of Clostridium difficile core components and divergent regions associated with host origin. J Bacteriol 191, 38813891.

Kallen, A. J., Thompson, A., Ristaino, P., Chapman, L., Nicholson, A., Sim, B. T., Lessa, F., Sharapov, U., Fadden, E. \& other authors (2009). Complete restriction of fluoroquinolone use to control an outbreak of Clostridium difficile infection at a community hospital. Infect Control Hosp Epidemiol 30, 264-272.

Kato, H., Kato, N., Katow, S., Maegawa, T., Nakamura, S. \& Lyerly, D. M. (1999). Deletions in the repeating sequences of the toxin A gene of toxin A-negative, toxin B-positive Clostridium difficile strains. FEMS Microbiol Lett 175, 197-203.

Keel, K., Brazier, J. S., Post, K. W., Weese, S. \& Songer, J. G. (2007). Prevalence of PCR ribotypes among Clostridium difficile isolates from pigs, calves, and other species. J Clin Microbiol 45, 1963-1964.

Kelly, C. P., Pothoulakis, C. \& LaMont, J. T. (1994). Clostridium difficile colitis. N Engl J Med 330, 257-262.

Killgore, G., Thompson, A., Johnson, S., Brazier, J., Kuijper, E., Pepin, J., Frost, E. H., Savelkoul, P., Nicholson, B. \& other authors (2008). Comparison of seven techniques for typing international epidemic strains of Clostridium difficile: restriction endonuclease analysis, pulsed-field gel electrophoresis, PCR-ribotyping, multilocus sequence typing, multilocus variable-number tandem-repeat analysis, amplified fragment length polymorphism, and surface layer protein A gene sequence typing. J Clin Microbiol 46, 431-437. 
Koehn, E. M. \& Kohen, A. (2010). Flavin-dependent thymidylate synthase: a novel pathway towards thymine. Arch Biochem Biophys 493, 96-102.

Koehn, E. M., Fleischmann, T., Conrad, J. A., Palfey, B. A., Lesley, S. A., Mathews, I. I. \& Kohen, A. (2009). An unusual mechanism of thymidylate biosynthesis in organisms containing the thyX gene. Nature 458, 919-923.

Lyras, D., O'Connor, J. R., Howarth, P. M., Sambol, S. P., Carter, G. P., Phumoonna, T., Poon, R., Adams, V., Vedantam, G. \& other authors (2009). Toxin B is essential for virulence of Clostridium difficile. Nature 458, 1176-1179.

Marsden, G. L., Davis, I. J., Wright, V. J., Sebaihia, M., Kuijper, E. J. \& Minton, N. P. (2010). Array comparative hybridisation reveals a high degree of similarity between UK and European clinical isolates of hypervirulent Clostridium difficile. BMC Genomics 11, 389.

McDonald, L. C., Killgore, G. E., Thompson, A., Owens, R. C., Jr, Kazakova, S. V., Sambol, S. P., Johnson, S. \& Gerding, D. N. (2005). An epidemic, toxin gene-variant strain of Clostridium difficile. $N$ Engl J Med 353, 2433-2441.

Merrigan, M., Venugopal, A., Mallozzi, M., Roxas, B., Viswanathan, V. K., Johnson, S., Gerding, D. N. \& Vedantam, G. (2010). Human hypervirulent Clostridium difficile strains exhibit increased sporulation as well as robust toxin production. J Bacteriol 192, 49044911.

Pépin, J., Valiquette, L., Alary, M. E., Villemure, P., Pelletier, A., Forget, K., Pépin, K. \& Chouinard, D. (2004). Clostridium difficileassociated diarrhea in a region of Quebec from 1991 to 2003: a changing pattern of disease severity. CMAJ 171, 466-472.

Pépin, J., Valiquette, L. \& Cossette, B. (2005). Mortality attributable to nosocomial Clostridium difficile-associated disease during an epidemic caused by a hypervirulent strain in Quebec. CMAJ 173, 1037-1042.

Pirs, T., Ocepek, M. \& Rupnik, M. (2008). Isolation of Clostridium difficile from food animals in Slovenia. J Med Microbiol 57, 790-792.

Pituch, H., Brazier, J. S., Obuch-Woszczatynski, P., Wultanska, D., Meisel-Mikolajczyk, F. \& Luczak, M. (2006). Prevalence and association of PCR ribotypes of Clostridium difficile isolated from symptomatic patients from Warsaw with macrolide-lincosamidestreptogramin B (MLSB) type resistance. J Med Microbiol 55, 207213.

Rupnik, M., Brazier, J. S., Duerden, B. I., Grabnar, M. \& Stubbs, S. L. (2001). Comparison of toxinotyping and PCR ribotyping of Clostridium difficile strains and description of novel toxinotypes. Microbiology 147, 439-447.
Rupnik, M., Wilcox, M. H. \& Gerding, D. N. (2009). Clostridium difficile infection: new developments in epidemiology and pathogenesis. Nat Rev Microbiol 7, 526-536.

Schwan, C., Stecher, B., Tzivelekidis, T., van Ham, M., Rohde, M., Hardt, W. D., Wehland, J. \& Aktories, K. (2009). Clostridium difficile toxin CDT induces formation of microtubule-based protrusions and increases adherence of bacteria. PLoS Pathog 5, e1000626.

Sciara, G., Kendrew, S. G., Miele, A. E., Marsh, N. G., Federici, L., Malatesta, F., Schimperna, G., Savino, C. \& Vallone, B. (2003). The structure of ActVA-Orf6, a novel type of monooxygenase involved in actinorhodin biosynthesis. EMBO J 22, 205-215.

Sebaihia, M., Wren, B. W., Mullany, P., Fairweather, N. F., Minton, N., Stabler, R., Thomson, N. R., Roberts, A. P., Cerdeño-Tárraga, A. M. \& other authors (2006). The multidrug-resistant human pathogen Clostridium difficile has a highly mobile, mosaic genome. Nat Genet 38, 779-786.

Söding, J. (2005). Protein homology detection by HMM-HMM comparison. Bioinformatics 21, 951-960.

Spigaglia, P. \& Mastrantonio, P. (2002). Molecular analysis of the pathogenicity locus and polymorphism in the putative negative regulator of toxin production (TcdC) among Clostridium difficile clinical isolates. J Clin Microbiol 40, 3470-3475.

Stabler, R. A., Gerding, D. N., Songer, J. G., Drudy, D., Brazier, J. S., Trinh, H. T., Witney, A. A., Hinds, J. \& Wren, B. W. (2006). Comparative phylogenomics of Clostridium difficile reveals clade specificity and microevolution of hypervirulent strains. J Bacteriol 188, 7297-7305.

Stabler, R. A., He, M., Dawson, L., Martin, M., Valiente, E., Corton, C., Lawley, T. D., Sebaihia, M., Quail, M. A. \& other authors (2009). Comparative genome and phenotypic analysis of Clostridium difficile 027 strains provides insight into the evolution of a hypervirulent bacterium. Genome Biol 10, R102.

Voth, D. E. \& Ballard, J. D. (2005). Clostridium difficile toxins: mechanism of action and role in disease. Clin Microbiol Rev 18, 247-263.

Warny, M., Pepin, J., Fang, A., Killgore, G., Thompson, A., Brazier, J., Frost, E. \& McDonald, L. C. (2005). Toxin production by an emerging strain of Clostridium difficile associated with outbreaks of severe disease in North America and Europe. Lancet 366, 1079-1084.

Weese, J. S., Wakeford, T., Reid-Smith, R., Rousseau, J. \& Friendship, R. (2010). Longitudinal investigation of Clostridium difficile shedding in piglets. Anaerobe 16, 501-504.

Zaiss, N. H., Rupnik, M., Kuijper, E. J., Harmanus, C., Michielsen, D., Janssens, K. \& Nübel, U. (2009). Typing Clostridium difficile strains based on tandem repeat sequences. BMC Microbiol 9, 6 .

Edited by: S. D. Bentley 